\title{
\& Research Square

\section{Blood eosinophil levels and prognosis of hospitalized patients with acute exacerbation of chronic obstructive pulmonary disease}

Songsong $\mathrm{Yu}$

Beijing Shijitan Hospital Capital Medical University

Jie Zhang

Beijing Shijitan Hospital, Capital Medical University

Qiuhong Fang

Beijing Chaoyang Hospital, Capital Medical University

Zhaohui Tong ( $\nabla$ tongzhaohuicy@sina.com)

Beijing Chaoyang Hospital

Research article

Keywords: eosinophil, chronic obstructive pulmonary disease, acute exacerbation, prognosis

Posted Date: February 25th, 2020

DOI: https://doi.org/10.21203/rs.2.24530/v1

License: (9) This work is licensed under a Creative Commons Attribution 4.0 International License.

Read Full License

Version of Record: A version of this preprint was published at The American Journal of the Medical

Sciences on July 1st, 2021. See the published version at https://doi.org/10.1016/j.amjms.2021.02.013. 


\section{Abstract}

Background: Studies about the clinical significance of high eosinophil levels in chronic obstructive pulmonary disease (COPD) are conflicting, and it has been less studied in hospitalized patients with acute exacerbation of COPD (AECOPD). This study was to examine blood eosinophil levels in relation to the prognosis of hospitalized patients with AECOPD.

Methods: This was a retrospective cohort study of patients with AECOPD as their primary diagnosis and admitted to Beijing Shijitan Hospital, Capital Medical University, from January 2010 to December 2016. The patients were assigned according to the proportion and count of eosinophil in peripheral blood at their first hospitalization. Patients were grouped as $\leq 100,100-300$, and $\geq 300$ eosinophils $/ \mu \mathrm{L}$ of peripheral blood. The use of glucocorticoids, duration of hospitalization, in-hospital mortality, and rehospitalization were examined.

Results: Compared with the 100-300 eosinophils/ $\mu \mathrm{L}$ group, the $\leq 100$ eosinophils/ $\mu \mathrm{L}$ group showed higher frequencies of fever, respiratory failure, and the use of systemic glucocorticoids. Eosinophil counts were not associated with in-hospital mortality and duration of hospitalization. The multivariable analysis showed that GOLD3/4 (odds ratio $(O R)=2.04,95 \% \mathrm{Cl}: 1.20-3.44, \mathrm{P}=0.008$ ), neutrophil count $(\mathrm{OR}=1.21$, 95\%Cl: 1.03-1.41, $\mathrm{P}=0.019)$, systemic glucocorticoids ( $\mathrm{OR}=1.84,95 \% \mathrm{Cl}: 1.41-2.98, \mathrm{P}=0.012)$, mechanical ventilation $(\mathrm{OR}=2.66,95 \% \mathrm{Cl}: 1.36-5.18, \mathrm{P}=0.004)$, and acute exacerbation in the past year before hospitalization $(\mathrm{OR}=2.03,95 \% \mathrm{Cl}: 1.27-3.23, \mathrm{P}=0.003)$ were independently associated with acute exacerbation within 1 year after discharge. Eosinophil count was not associated with acute exacerbation within 1 year after discharge.

Conclusion: Peripheral blood eosinophil counts are not associated with the 1-year AECOPD prognosis.

\section{Background}

Chronic obstructive pulmonary disease (COPD) is characterized by significant airflow limitation associated with a chronic inflammatory response in the airways and lungs, resulting in the destruction of lung tissue [1]. It commonly affects adults $>40$ years old who smoke, with an estimated worldwide prevalence of $4 \%-10 \%[1,2]$. The disease course is usually progressive, with a long-term decline in lung function [3]. It is a preventable and treatable disease commonly associated with co-morbidities (such as cardiovascular disease) and significant systemic consequences (such as skeletal muscle dysfunction) [1]. COPD has several complications, including acute exacerbation, respiratory failure, and pulmonary hypertension. The 4 -year mortality rates range from $28 \%$ for mild-to-moderate COPD to $62 \%$ for moderateto-severe COPD $[4,5]$.

Acute exacerbation of COPD (AECOPD) is characterized by an acute worsening in baseline symptoms such as cough, dyspnea, and/or sputum production beyond normal daily variations to the extent where it requires a change in therapy $[1,6]$. AECOPD is commonly caused by viral or bacterial infections, including pneumonia and air pollution $[1,6,7]$. In-hospital mortality for patients with AECOPD is around $2.5 \%$ in 
general and $10 \%$ with hypercarbia $[1,8]$. All-cause mortality within 3 years of hospitalization may be as high as $49 \%[1,6]$.

The pathogenesis of COPD involves inflammation-induced structural changes that result in small airway remodeling and narrowing and parenchymal destruction, decreased elastic recoil, and reduction in the ability of the airways to remain open [1]. COPD progression is associated with the accumulation of inflammatory mucous exudate and inflammatory exudate in the airway wall [9]. COPD is a heterogeneous disease among patients. Eosinophil infiltration was previously thought to be limited to asthma, but it is now known that eosinophil infiltration constitutes a subset of COPD [10-13], with about $37 \%$ of patients with persistently elevated eosinophil counts [14]. Among all patients with COPD, the patients with eosinophil infiltration show the greatest response to corticosteroid therapy [10-13]. Eosinophil numbers are increased in the sputum and peripheral blood during exacerbation episodes $[15,16]$.

Nevertheless, the exact role of eosinophil counts in the management of patients with COPD remains controversial. The Copenhagen City Lung study showed that high peripheral eosinophil counts $(>340$ cells $/ \mu \mathrm{L}$ ) were associated with increased risk of AECOPD [17], as supported by other studies [15, 16], but such association was not observed when using a threshold of $2 \%[14,17,18]$. Further contributing to the controversy, elevated blood eosinophil counts are associated with better lung function, quality of life, and mortality rates $[14,19,20]$. Eosinopenia is associated with sepsis, pneumonia, and worse prognosis of AECOPD [21-23].

Studies are lacking about the clinical significance of high eosinophil levels in hospitalized patients with AECOPD. Therefore, the aim of the present study was to examine blood eosinophil levels in relation to the prognosis of hospitalized patients with acute exacerbation of chronic obstructive pulmonary disease.

\section{Methods}

\section{Study design and patients}

This was a retrospective cohort study of patients with AECOPD as their primary diagnosis and admitted to Beijing Shijitan Hospital, Capital Medical University, from January 2010 to December 2016. This study was approved by the Ethics Committee of Beijing Shijitan Hospital, Capital Medical University (\#2018-1066). The informed consent was waived because of the retrospective study.

The inclusion criteria were: 1) the diagnosis and hospitalization indications of AECOPD were consistent with the Global Initiative for Chronic Obstructive Lung Disease (GOLD) [1]; and 2) complete clinical data, including one-year follow-up data. The exclusion criteria were: 1) bronchiectasis, pulmonary interstitial fibrosis, active tuberculosis, lung cancer, or other diseases; 2) diseases of the blood and endocrine system that affect blood eosinophil count; or 3) confirmed history of bronchial asthma.

\section{Grouping and definitions}


All patients matching the criteria during the study period were included. The patients were assigned according to the proportion and count of eosinophil in peripheral blood at their first hospitalization: $\leq 100$ cells $/ \mu \mathrm{L}, 100<\mathrm{EO}<300$ cells $/ \mu \mathrm{L}$, and $\geq 300$ cells $/ \mu \mathrm{L}$. COPD was staged as GOLD1 (FEV1 $>80 \%$ of predicted value), GOLD2 ( $50 \% \leq \mathrm{FEV} 1<80 \%$ of predicted value), GOLD3 $(30 \% \leq \mathrm{FEV} 1<50 \%$ of predicted value), and GOLD4 (FEV1 $<30 \%$ of predicted value).

\section{Data collection}

Basic data and clinical manifestations included sex, age, history of disease (hypertension, type II diabetes, ischemic heart disease, asthma, tuberculosis, and osteoporosis), history of smoking, course of COPD, COPD stage, use of inhaled corticosteroids in a stable period, and acute exacerbation in the past year before hospitalization were collected. The main clinical symptoms of acute exacerbation included wheezing, coughing, and expectoration with/without purulent sputum were also collected.

Results of the first examination after admission were collected, including white blood cell count, neutrophil percentage and count, eosinophil percentage and count, arterial blood gas analysis, sputum culture, chest imaging examination, and lung function (FEV1/FVC, FEV1\%, bronchodilatation test).

Treatment and outcome included patients' use of glucocorticoids during hospitalization, including duration of use and total use, duration of hospitalization, and hospital mortality.

\section{Follow-up}

All patients were followed at 30 days and 1 year after discharge by telephone. Follow-up was censored on 2017.12.31. Whether the patient was hospitalized again due to acute exacerbation within 30 days and 1 year after discharge was recorded (acute exacerbation of re-hospitalization refers to coughing, sputum expectoration, or wheezing).

\section{Statistical analysis}

SPSS 20.0 (IBM, Armonk, NY, USA) was used to analyze the data. Categorical data are expressed as n (\%) and were analyzed using the chi-square test. Continuous data are presented as means \pm standard deviation (SD) and were tested using ANOVA with the LSD post hoc test. Multivariable logistic regression analysis was used to analyze the association of eosinophil counts and percentage with patient outcomes. The regression method was Backward and the included variables had to be significant in the univariable analyses. The results are shown as odds ratio (OR) and $95 \%$ confidence interval $(95 \% \mathrm{Cl})$. Two-sided P-values $<0.05$ were considered statistically significant.

\section{Results}

\section{Characteristics of the patients}


A total of 1287 patients with AECOPD were first identified, and 132 were excluded because of concomitant asthma and 647 because they were readmissions. Among the 508 evaluable patients, 328, 142 , and 38 were in the $<100,100-300$, and $>300$ eosinophils/ $\mu \mathrm{L}$ groups, respectively (Figure 1 ). Table 1 presents the characteristics of the patients. There were no differences among the three groups, except that the $\leq 100$ eosinophils/ $\mu \mathrm{L}$ group, compared with the 100-300 eosinophils/ $\mu \mathrm{L}$ group, showed higher frequencies of fever $(50.6 \%$ vs. $35.2 \%, P=0.002)$ and respiratory failure $(30.5 \%$ vs. $20.4 \%, P=0.025)$.

\section{Blood test results}

Table 2 presents the results of the blood tests. There were no differences among the three groups regarding white blood cells $(P=0.10), p H(P=0.31), P C O 2(P=0.89)$, and FEV1 ( $P=0.59)$. Compared with the 100-300 eosinophils/ $\mu \mathrm{L}$ group, the $\leq 100$ eosinophils/ $\mu \mathrm{L}$ group showed higher neutrophil percentage (74.85 $\pm 11.5 \%$ vs. $67.8 \pm 9.0 \%, P<0.05)$ and higher neutrophil count $(6.33 \pm 3.97$ vs. $5.01 \pm 2.08, P<0.05)$. Compared with the $\geq 300$ eosinophils/ $\mu \mathrm{L}$ group, the $100-300$ eosinophils/ $\mu \mathrm{L}$ groups showed higher neutrophil percentage $(67.8 \pm 9.0$ vs. $62.4 \pm 13.0 \%, P<0.05)$, lower neutrophil count $(5.01 \pm 2.08$ vs. $5.20 \pm 2.28, P<0.05)$, and higher $\mathrm{PO} 2(71.9 \pm 27.7$ vs. $66.6 \pm 30.3, \mathrm{P}<0.05)$.

\section{Clinical outcomes}

Table 3 presents the clinical outcomes. There were no differences among the three groups regarding the admission rate to the ICU ( $P=0.06)$, mechanical ventilation $(P=0.24)$, the use of ICS $(P=0.95)$, in-hospital mortality $(P=0.98)$, duration of hospitalization $(P=0.77)$, acute exacerbation within 30 days after discharge $(P=0.45)$, and acute exacerbation within 1 year after discharge $(P=0.46)$. Compared with the 100-300 eosinophils/ $\mu \mathrm{L}$ group, the $\leq 100$ eosinophils/ $\mu \mathrm{L}$ group showed a higher use of systemic glucocorticoids ( $27.4 \%$ vs. $14.8 \%, P=0.003)$. Eosinophil counts were not associated with in-hospital mortality and duration of hospitalization.

\section{Factors associated with acute exacerbation within 1 year after discharge}

Table 4 shows the univariable and multivariable analyses of the factors associated with acute exacerbation within 1 year after discharge. GOLD3/4 (OR=2.04, 95\%Cl: 1.20-3.44, $\mathrm{P}=0.008)$, neutrophil count (OR=1.21, 95\%Cl: 1.03-1.41, $\mathrm{P}=0.019)$, systemic glucocorticoids $(\mathrm{OR}=1.84,95 \% \mathrm{Cl}: 1.41-2.98$, $\mathrm{P}=0.012)$, mechanical ventilation $(\mathrm{OR}=2.66,95 \% \mathrm{Cl}$ : $1.36-5.18, \mathrm{P}=0.004)$, and acute exacerbation in the past year before hospitalization $(\mathrm{OR}=2.03,95 \% \mathrm{Cl}: 1.27-3.23, \mathrm{P}=0.003)$ were independently associated with acute exacerbation within 1 year after discharge. Eosinophil count was not associated with acute exacerbation within 1 year after discharge.

\section{Discussion}

Studies about the clinical significance of high eosinophil levels in COPD are conflicting, and it has been even less studied in hospitalized patients with AECOPD. Therefore, the aim of the present study was to examine blood eosinophil levels in relation to the prognosis of hospitalized patients with acute 
exacerbation of chronic obstructive pulmonary disease. The results suggest that peripheral blood eosinophil counts are not associated with the 1-year prognosis of AECOPD.

Eosinophils play important roles in inflammatory diseases, especially the initiation and modulation of inflammation [24]. Their role in diseases like asthma has been known for a long time, but they are now known to play roles in diseases like COPD, inflammatory bowel diseases, autoimmune myocarditis, and primary biliary cirrhosis, among others $[10-13,24,25]$. The mechanisms for their association with autoimmune diseases include degranulation of their granule content, autoantibody-dependent cellmediated cytotoxicity, degradation of the extracellular matrix, cytokine secretion, antigen presentation, induction of fibrosis; and role in thrombosis [24, 25]. Patients with underlying eosinophil-associated diseases might be at higher risk of autoimmune diseases [24-27].

COPD is a heterogeneous disease that differs in etiology, progression, and prognosis from one patient to the other $[28,29]$. About $37 \%$ of patients with COPD display a persistently elevated eosinophil count [14]. Despite the association of eosinophils with inflammatory and autoimmune diseases, the exact clinical implications of those elevated counts in COPD remain controversial [24, 25]. On the one hand, the Copenhagen City Lung study showed that eosinophil count $>340$ cells $/ \mu \mathrm{L}$ were associated with a higher risk of AECOPD, but that the threshold of $2 \%$ was not [17], as supported by Singh et al. [14] and Zysman et al. [18]. In addition, eosinophil counts are increased in the sputum and peripheral blood during exacerbation episodes $[15,16]$. Surprisingly when we consider their role in inflammation and autoimmune diseases, elevated peripheral blood eosinophils have been associated with better lung function, improved quality of life, and lower mortality rates in patients with $\operatorname{COPD}[14,19,20]$, but this could be due to the fact that patients with COPD and high eosinophil counts respond better to corticosteroids than patients with lower eosinophil counts $[10-13,19,30,31]$. Low eosinophil counts have also been associated with a higher occurrence of complications of AECOPD, including sepsis, pneumonia, longer hospitalization, and mortality $[21-23,32]$.

In the present study, the patients were grouped according to eosinophil counts of $\leq 100,100-300$, and $\geq 300$ cells $/ \mu \mathrm{L}$, and no association was observed between eosinophil count and acute exacerbation within 1 year after discharge. A recent study suggested that eosinophil counts could predict exacerbation events in patients with COPD, but only in ex-smokers [33]. Brusselle et al. [34] showed that eosinophil counts could predict the recurrence of AECOPD in patients who already had a history of AECOPD episodes. Therefore, because COPD is a complex disease, it is possible that eosinophil counts are associated with the prognosis of AECOPD only in subgroups of patients. In addition, future studies should account for the environmental factors associated with the development of COPD and AECOPD [35]. On the other hand, stratification of the patients of the SPIROMICS study according to eosinophil counts showed no association between blood eosinophil counts and AECOPD, while sputum eosinophil counts were associated with AECOPD [36], therefore supporting the present study.

This study has limitations. The sample size was relatively small and from a single center. In addition, environmental factors like air pollution were not controlled for, and it is known that air pollution is 
elevated in Chinese cities [37], limiting the generalizability of the study. Finally, due to the retrospective nature of the study, only the data that were included in the patient charts could be analyzed.

\section{Conclusion}

Peripheral blood eosinophil counts are not associated with the 1-year AECOPD prognosis.

\section{Abbreviations}

COPD: chronic obstructive pulmonary disease; AECOPD: acute exacerbation of COPD; GOLD: Global Initiative for Chronic Obstructive Lung Disease; SD: standard deviation; OR: odds ratio; $95 \% \mathrm{Cl}$ : 95\% confidence interval.

\section{Declarations}

\section{Ethics approval and consent to participate}

This study was approved by the Ethics Committee of Beijing Shijitan Hospital, Capital Medical University (\#2018-10-66). The informed consent was waived because of the retrospective study.

\section{Consent for publication}

Not applicable

\section{Availability of data and materials}

The datasets used and/or analysed during the current study are available from the corresponding author on reasonable request.

\section{Competing interests}

The authors declare that they have no competing interests

\section{Funding}

This study was funded by Beijing Municipal Science \&Technology Commission [NO.

Z181100001718185]. The funding bodies had no role in the design of the study and collection, analysis, and interpretation of data and in writing the manuscript.

\section{Authors' contributions}

ZHT have made contributions to the conception; QHF and SSY have made contributions to design of the work; SSY and JZ have made contributions to the collection, acquisition, analysis; SSY have drafted the work or substantively revised it. All authors read and approved the final manuscript. 
Acknowledgments

Not applicable

\section{References}

1. Global Initiative for Chronic Obstructive Lung Disease (GOLD): Global strategy for the diagnosis, management, and prevention of chronic obstructive pulmonary disease. Fontana: Global Initiative for Chronic Obstructive Lung Disease, Inc.; 2019.

2. Halbert RJ, Isonaka S, George D, Iqbal A. Interpreting COPD prevalence estimates: what is the true burden of disease? Chest 2003, 123(5):1684-92.

3. McDonough JE, Yuan R, Suzuki M, Seyednejad N, Elliott WM, Sanchez PG et al. Small-airway obstruction and emphysema in chronic obstructive pulmonary disease. N Engl J Med 2011, 365(17):1567-75.

4. Ford ES, Croft JB, Mannino DM, Wheaton AG, Zhang X, Giles WH. COPD surveillance-United States, 1999-2011. Chest 2013, 144(1):284-305.

5. Collaborators GBDCRD. Global, regional, and national deaths, prevalence, disability-adjusted life years, and years lived with disability for chronic obstructive pulmonary disease and asthma, 19902015: a systematic analysis for the Global Burden of Disease Study 2015. Lancet Respir Med 2017, 5(9):691-706.

6. Evensen AE. Management of COPD exacerbations. Am Fam Physician 2010, 81(5):607-13.

7. Ko FW, Ip M, Chan PK, Fok JP, Chan MC, Ngai JC et al. A 1-year prospective study of the infectious etiology in patients hospitalized with acute exacerbations of COPD. Chest 2007, 131(1):44-52.

8. Patil SP, Krishnan JA, Lechtzin N, Diette GB. In-hospital mortality following acute exacerbations of chronic obstructive pulmonary disease. Arch Intern Med 2003, 163(10):1180-6.

9. Hogg JC, Chu F, Utokaparch S, Woods R, Elliott WM, Buzatu L et al. The nature of small-airway obstruction in chronic obstructive pulmonary disease. N Engl J Med 2004, 350(26):2645-53.

10. Brightling CE, McKenna S, Hargadon B, Birring S, Green R, Siva R et al. Sputum eosinophilia and the short term response to inhaled mometasone in chronic obstructive pulmonary disease. Thorax 2005 , 60(3):193-8.

11. Brightling CE, Monteiro W, Ward R, Parker D, Morgan MD, Wardlaw AJ et al. Sputum eosinophilia and short-term response to prednisolone in chronic obstructive pulmonary disease: a randomised controlled trial. Lancet 2000, 356(9240):1480-5.

12. Leigh R, Pizzichini MM, Morris MM, Maltais F, Hargreave FE, Pizzichini E. Stable COPD: predicting benefit from high-dose inhaled corticosteroid treatment. Eur Respir J 2006, 27(5):964-71.

13. Pizzichini E, Pizzichini MM, Gibson P, Parameswaran K, Gleich GJ, Berman L et al. Sputum eosinophilia predicts benefit from prednisone in smokers with chronic obstructive bronchitis. Am J Respir Crit Care Med 1998, 158(5 Pt 1):1511-7. 
14. Singh D, Kolsum U, Brightling CE, Locantore N, Agusti A, Tal-Singer R et al. Eosinophilic inflammation in COPD: prevalence and clinical characteristics. Eur Respir J 2014, 44(6):1697-700.

15. Bafadhel M, McKenna S, Terry S, Mistry V, Reid C, Haldar P et al. Acute exacerbations of chronic obstructive pulmonary disease: identification of biologic clusters and their biomarkers. Am J Respir Crit Care Med 2011, 184(6):662-71.

16. Papi A, Luppi F, Franco F, Fabbri LM. Pathophysiology of exacerbations of chronic obstructive pulmonary disease. Proc Am Thorac Soc 2006, 3(3):245-51.

17. Vedel-Krogh S, Nielsen SF, Lange P, Vestbo J, Nordestgaard BG. Blood Eosinophils and Exacerbations in Chronic Obstructive Pulmonary Disease. The Copenhagen General Population Study. Am J Respir Crit Care Med 2016, 193(9):965-74.

18. Zysman M, Deslee G, Caillaud D, Chanez P, Escamilla R, Court-Fortune I et al. Relationship between blood eosinophils, clinical characteristics, and mortality in patients with COPD. Int J Chron Obstruct Pulmon Dis 2017, 12:1819-24.

19. Barnes NC, Sharma R, Lettis S, Calverley PM. Blood eosinophils as a marker of response to inhaled corticosteroids in COPD. Eur Respir J 2016, 47(5):1374-82.

20. Suzuki M, Makita H, Konno S, Shimizu K, Kimura H, Kimura H et al. Asthma-like Features and Clinical Course of Chronic Obstructive Pulmonary Disease. An Analysis from the Hokkaido COPD Cohort Study. Am J Respir Crit Care Med 2016, 194(11):1358-65.

21. Holland M, Alkhalil M, Chandromouli S, Janjua A, Babores M. Eosinopenia as a marker of mortality and length of stay in patients admitted with exacerbations of chronic obstructive pulmonary disease. Respirology 2010, 15(1):165-7.

22. Steer J, Gibson J, Bourke SC. The DECAF Score: predicting hospital mortality in exacerbations of chronic obstructive pulmonary disease. Thorax 2012, 67(11):970-6.

23. Pavord ID, Lettis S, Anzueto A, Barnes N. Blood eosinophil count and pneumonia risk in patients with chronic obstructive pulmonary disease: a patient-level meta-analysis. Lancet Respir Med 2016, 4(9):731-41.

24. Diny NL, Rose NR, Cihakova D. Eosinophils in Autoimmune Diseases. Front Immunol 2017, 8:484.

25. Ramirez GA, Yacoub MR, Ripa M, Mannina D, Cariddi A, Saporiti N et al. Eosinophils from Physiology to Disease: A Comprehensive Review. Biomed Res Int 2018, 2018:9095275.

26. Lecouffe-Desprets M, Groh M, Bour B, Le Jeunne C, Puechal X. Eosinophilic gastrointestinal disorders associated with autoimmune connective tissue disease. Joint Bone Spine 2016, 83(5):479-84.

27. Tedeschi A, Asero R. Asthma and autoimmunity: a complex but intriguing relation. Expert Rev Clin Immunol 2008, 4(6):767-76.

28. Barrecheguren M, Miravitlles M. COPD heterogeneity: implications for management. Multidiscip Respir Med 2016, 11:14.

29. Sidhaye VK, Nishida K, Martinez FJ. Precision medicine in COPD: where are we and where do we need to go? Eur Respir Rev 2018, 27(149). 
30. Siddiqui SH, Pavord ID, Barnes NC, Guasconi A, Lettis S, Pascoe S et al. Blood eosinophils: a biomarker of COPD exacerbation reduction with inhaled corticosteroids. Int $\mathrm{J}$ Chron Obstruct Pulmon Dis 2018, 13:3669-76.

31. Pavord ID, Lettis S, Locantore N, Pascoe S, Jones PW, Wedzicha JA et al. Blood eosinophils and inhaled corticosteroid/long-acting beta-2 agonist efficacy in COPD. Thorax 2016, 71(2):118-25.

32. MacDonald MI, Osadnik CR, Bulfin L, Hamza K, Leong P, Wong A et al. Low and High Blood Eosinophil Counts as Biomarkers in Hospitalized Acute Exacerbations of COPD. Chest 2019, 156(1):92-100.

33. Kerkhof M, Sonnappa S, Postma DS, Brusselle G, Agusti A, Anzueto A et al. Blood eosinophil count and exacerbation risk in patients with COPD. Eur Respir J 2017, 50(1).

34. Brusselle G, Pavord ID, Landis S, Pascoe S, Lettis S, Morjaria N et al. Blood eosinophil levels as a biomarker in COPD. Respir Med 2018, 138:21-31.

35. Kim WJ, Lee CY. Environmental exposures and chronic obstructive pulmonary disease. Mol Cell Toxicol 2017, 13(3):251-5.

36. Hastie AT, Martinez FJ, Curtis JL, Doerschuk CM, Hansel NN, Christenson S et al. Association of sputum and blood eosinophil concentrations with clinical measures of COPD severity: an analysis of the SPIROMICS cohort. Lancet Respir Med 2017, 5(12):956-67.

37. Gao N, Li C, Ji J, Yang Y, Wang S, Tian X et al. Short-term effects of ambient air pollution on chronic obstructive pulmonary disease admissions in Beijing, China (2013-2017). Int J Chron Obstruct Pulmon Dis 2019, 14:297-309.

\section{Tables}

Table 1. Characteristics of the patients 
Variables

$\leq 100$ cells $/ \mu \mathrm{L} \quad 100-300$ cells $/ \mu \mathrm{L} \quad \geq 300$ cells $/ \mu \mathrm{L} \quad \mathrm{P}$

$$
(\mathrm{N}=328) \quad(\mathrm{N}=142) \quad(\mathrm{N}=38)
$$

Age (years)

$76.5 \pm 8.8$

$76.4 \pm 8.9$

$75.7 \pm 8.6$

0.875

Sex (male)

$229(69.8 \%) \quad 107(75.4 \%)$

$30(78.9 \%) \quad 0.290$

Course of COPD (months)

$16.3 \pm 13.6 \quad 15.2 \pm 12.8$

$17.1 \pm 12.0$

0.618

History of smoking

$244(74.4 \%) \quad 111(78.2 \%)$

$33(86.8 \%)$

0.194

GOLD3/4

$219(66.8 \%) \quad 90$ (63.4\%)

$25(65.8 \%)$

0.777

Fever

$166(50.6 \%) \quad 50(35.2 \%)^{a}$

$14(36.8 \%)$

0.005

Symptoms

\begin{tabular}{lcccc}
\multicolumn{1}{c}{ Cough, expectoration } & $43(13.1 \%)$ & $17(12.0 \%)$ & $6(15.8 \%)$ & $<0.001$ \\
\hline Wheezing & $46(14.0 \%)$ & $19(13.4 \%)$ & $5(13.2 \%)$ & 0.976 \\
\hline Both & $239(72.9 \%)$ & $106(74.6 \%)$ & $27(71.1 \%)$ & 0.902 \\
\hline Respiratory failure & $100(30.5 \%)$ & $29(20.4 \%)^{a}$ & $6(15.8 \%)^{a}$ & 0.022 \\
\hline Hypertension & $188(57.3 \%)$ & $76(53.5 \%)$ & $21(55.3 \%)$ & 0.744 \\
\hline $\begin{array}{l}\text { Type 2 diabetes } \\
\text { Ischemic cardiomyopathy }\end{array}$ & $148(45.1 \%)$ & $61(43.0 \%)$ & $17(44.7 \%)$ & 0.910 \\
\hline $\begin{array}{l}\text { Osteoporosis } \\
\text { Previous tuberculosis }\end{array}$ & $74(22.6 \%)$ & $37(26.1 \%)$ & $7(18.4 \%)$ & 0.546
\end{tabular}

Imaging manifestations 
Chronic bronchitis

209 (63.7\%) 95 (66.9\%)

$25(65.8 \%)$

0.795

Pneumonia

$90(27.4 \%)$

$31(21.8 \%)$

$8(21.1 \%)$

0.358

ICS in a stable period

$38(11.6 \%)$

$13(9.2 \%)$

$1(2.6 \%)$

0.200

EO: eosinophils; COPD: chronic obstructive pulmonary disease; GOLD: Global Initiative for Chronic Obstructive Lung Disease; ICS: inhaled corticosteroids; ICU: intensive care unit.

$\mathrm{a}_{\mathrm{P}}<0.05$ vs. the $\leq 100$ eosinophils/ $\mu \mathrm{L}$ group.

Table 2. Blood and pulmonary test results of patients hospitalized for AECOPD and according to eosinophil levels at admission 


\begin{tabular}{|c|c|c|c|c|}
\hline Variables & $\begin{array}{l}\mathrm{EO} \leq 100 / \mu \mathrm{l} \\
(\mathrm{N}=328)\end{array}$ & $\begin{array}{l}100<\mathrm{EO}<300 / \mu \mathrm{l} \\
(\mathrm{N}=142)\end{array}$ & $\begin{array}{c}\mathrm{EO} \geq 300 / \mu \mathrm{l} \\
(\mathrm{N}=38)\end{array}$ & $\mathrm{P}$ \\
\hline WBC $\left(\times 10^{9} / \mathrm{L}\right)$ & $7.83 \pm 3.97$ & $7.20 \pm 2.34$ & $8.45 \pm 4.56$ & 0.096 \\
\hline $\mathrm{NE} \%$ & $74.84 \pm 11.53$ & $67.78 \pm 9.02^{\mathrm{a}}$ & $62.40 \pm 13.04^{\mathrm{ab}}$ & $<0.001$ \\
\hline $\begin{array}{l}\text { NE count } \\
\left(\times 10^{9} / \mathrm{L}\right)\end{array}$ & $6.33 \pm 3.97$ & $5.01 \pm 2.08^{a}$ & $5.20 \pm 2.28^{a b}$ & $<0.001$ \\
\hline $\mathrm{EO} \%$ & $\begin{array}{l}0.500(0.200- \\
1.100)\end{array}$ & $\begin{array}{l}2.550(1.800- \\
3.300)^{\mathrm{a}}\end{array}$ & $\begin{array}{l}5.000(3.775- \\
7.600)^{a b}\end{array}$ & $<0.001$ \\
\hline EO count $(/ \mu \mathrm{l})$ & $39.55 \pm 31.97$ & $177.02 \pm 51.38^{\mathrm{a}}$ & $581.42 \pm 392.28^{a b}$ & $<0.001$ \\
\hline $\mathrm{pH}$ & $7.09 \pm 1.50$ & $6.84 \pm 1.99$ & $6.44 \pm 2.54$ & 0.311 \\
\hline $\mathrm{PO}_{2}(\mathrm{mmHg})$ & $73.69 \pm 25.40$ & $71.87 \pm 27.67$ & $66.62 \pm 30.27^{\mathrm{ab}}$ & 0.007 \\
\hline $\mathrm{PCO}_{2}(\mathrm{mmHg})$ & $43.13 \pm 16.08$ & $38.68 \pm 15.33$ & $34.02 \pm 14.29$ & 0.894 \\
\hline $\begin{array}{l}\text { FEV1\% } \\
\text { predicted }\end{array}$ & $52.05 \pm 19.20$ & $53.84 \pm 17.69$ & $49.33 \pm 15.41$ & 0.591 \\
\hline
\end{tabular}

EO: eosinophils; WBC: white blood cells; NE: neutrophils; $\mathrm{PO}_{2}$ : partial pressure of oxygen; $\mathrm{PCO}_{2}$ : partial pressure of carbon dioxide; FEV1: forced expiratory volume in 1 second. ${ }^{\mathrm{a}} \mathrm{P}<0.05$ vs. the $\leq 100$ eosinophils $/ \mu \mathrm{L}$ group; ${ }^{\mathrm{b}} \mathrm{P}<0.05$ vs. the $100-300$ eosinophils $/ \mu \mathrm{L}$ group.

Table 3. Clinical outcomes of patients with AECOPD after hospitalization and according to the blood eosinophil levels 
variables

$$
\begin{aligned}
& \mathrm{EO} \leq 100 / 100<\mathrm{EO}<300 / \mu \mathrm{l} \quad \mathrm{EO} \geq 300 / \mu \mathrm{l} \quad \mathrm{P} \\
& \mu l \quad(\mathrm{~N}=142) \quad(\mathrm{N}=38)
\end{aligned}
$$

$(\mathrm{N}=328)$

Admission to ICU

41

$10(7.0 \%)$

$1(2.6 \%)$

0.055

(12.5\%)

ICS

264

$113(79.6 \%)$

$31(81.6 \%)$

0.954 (80.5\%)

Mechanical ventilation

$32(9.8 \%) \quad 14$ (9.9\%)

$1(2.6 \%)$

0.240

Systemic glucocorticoids

90

$21(14.8 \%)^{\mathrm{a}}$

$9(23.7 \%)$

0.012

(27.4\%)

In-hospital mortality

$10(3.0 \%) \quad 4(2.8 \%)$

$1(2.6 \%)$

0.983

Duration of hospitalization (days)

$10.8 \pm 9.9$

$11.4 \pm 13.4$

$10.0 \pm 4.8$

0.766

Acute exacerbation within 30 days

$14(4.4 \%) \quad 3(2.2 \%)$

$1(2.7 \%)$

0.454

after discharge

Acute exacerbation within 1 year

99

$35(25.4 \%)$

$13(35.1 \%)$

0.461

after discharge

$(31.1 \%)$

EO: eosinophils; ICU: intensive care unit; ICS: inhaled corticosteroids.

${ }^{\text {a }} \mathrm{P}<0.05$ vs. the $\leq 100$ eosinophils/ $\mu \mathrm{L}$ group

Table 4. Univariable and multivariable analyses of factors associated with acute exacerbation within 1 year after discharge 
Variables

Univariable Multivariable

$\begin{array}{llllll}\text { OR } & 95 \% \text { CI } & P & \text { OR } & 95 \% C I & P\end{array}$

Age

$1.011 \quad 0.989-\quad 0.338$

1.034

Sex

$1.606 \quad 1.057-\quad 0.026$

2.440

History of smoking

$0.994 \quad 0.632-\quad 0.979$

1.564

GOLD 3/4

3.397

$2.114-$

$<0.001$

2.035

1.203- 0.008

5.459

3.443

Fever

1.265

$0.725-$

0.736

1.575

Admission to ICU

$3.527 \quad 1.875-<0.001$

6.633

Respiratory failure

$2.418 \quad 1.575-<0.001$

3.711

Hypertension

$1.045 \quad 0.708-\quad 0.826$

1.542

Type 2 diabetes

$1.504 \quad 0.956-\quad 0.078$

2.365

Previous tuberculosis

$1.374 \quad 0.884-\quad 0.158$

2.136

Ischemic cardiomyopathy

$1.496 \quad 1.015-\quad 0.042$ 
Osteoporosis

Chronic bronchitis on CT

Pneumonia on CT

$\mathrm{pH}$

$\mathrm{PaO}_{2}$

$\mathrm{PaCO}_{2}$

Count of WBC

Count of NE

Count of EO

$$
\begin{gathered}
\mathrm{EO} \leq 100 / \mu \mathrm{l} \\
100<\mathrm{EO}<300 / \mu \mathrm{l}
\end{gathered}
$$

$\mathrm{EO} \geq 300 / \mu \mathrm{l}$
$1.256 \quad 0.569-$
0.572
2.772
0.734
$0.492-$
0.131
1.096
$1.017 \quad 0.652-\quad 0.941$
1.587
$1.066 \quad 0.945-\quad 0.300$
1.203
$1.003 \quad 0.995-\quad 0.464$
1.010
$1.030 \quad 1.017-<0.001$
1.043
$1.015 \quad 0.964-\quad 0.566$
1.069

1.049

0.994- 0.082

$$
\begin{array}{ccc}
0.812 & 0.548- & 0.302 \\
& 1.205 & \\
& & \\
1.198 & 0.586- & 0.620 \\
& 2.451 &
\end{array}
$$


ICS in a stable period

Systemic glucocorticoids

Mechanical ventilation

Acute exacerbation in the past year

before hospitalization
$0.979 \quad 0.518-\quad 0.947$

1.848

$2.663 \quad 1.716-\quad<0.001 \quad 1.843 \quad 1.414-\quad 0.012$

4.131

2.978

$4.327 \quad 2.269$

$<0.001$

2.656

$1.363-0.004$

8.252

5.175

2.900

1.902-

$<0.00$

2.025

$1.269-0.003$

4.422

ICU: intensive care unit; ICS: inhaled corticosteroids; CT: computed tomography; $\mathrm{PaO}_{2}$ : partial pressure of oxygen; $\mathrm{PaCO}_{2}$ : partial pressure of carbon dioxide; WBC: white blood cells; NE: neutrophils; EO: eosinophils; AE: acute exacerbation.

\section{Figures}




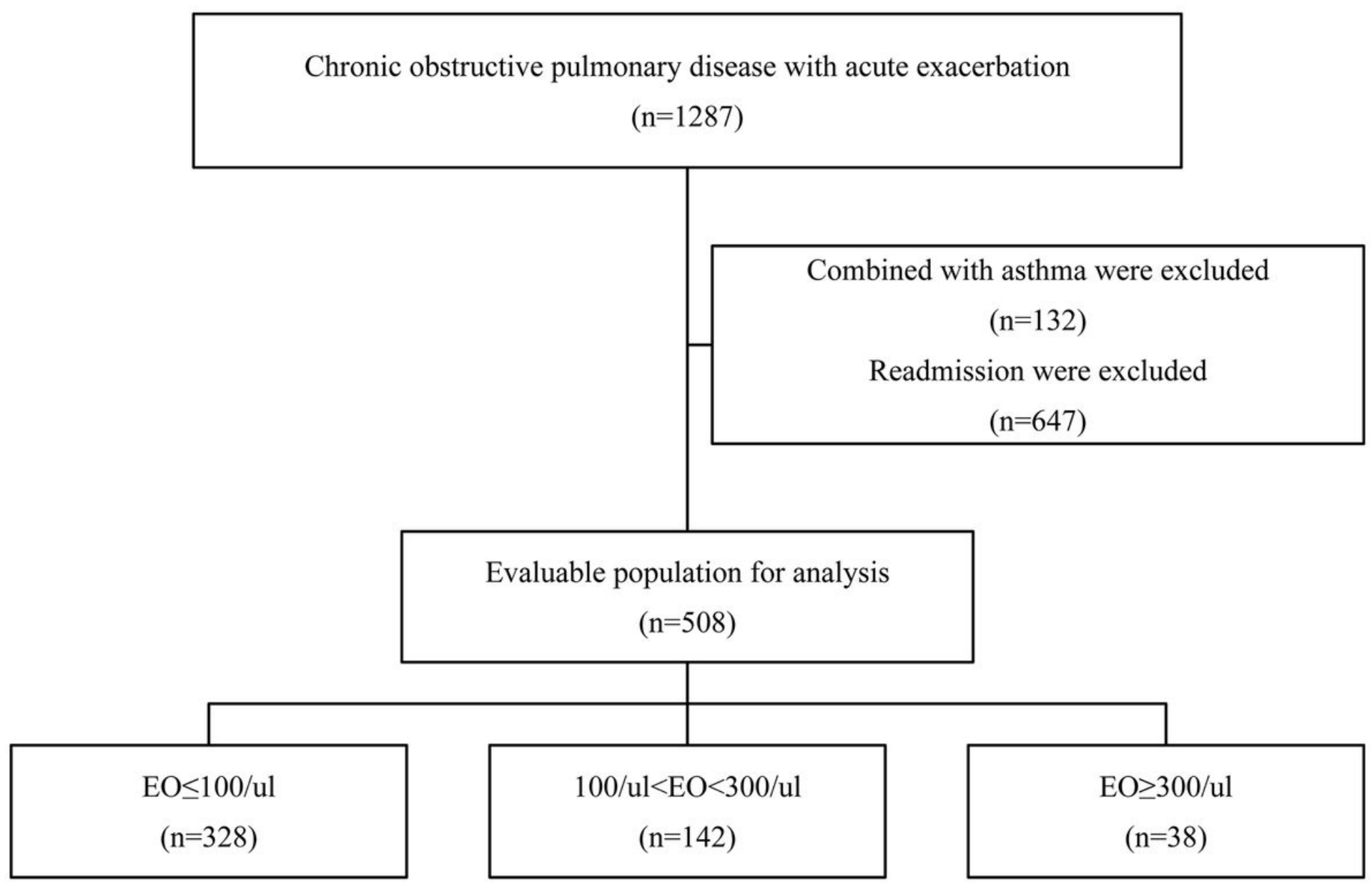

Figure 1

Patient flowchart and selection process 